\title{
Análise da Vulnerabilidade de Adolescentes à Infecção pelo Hiv/Aids em Iguatu - CE
}

Natália Bastos Ferreira ${ }^{l}$; Israel Ferreira da Costa $^{2}$; Raimundo Tavares de Luna Neto ${ }^{3}$; Leonardo Félix de Freitas ${ }^{4}$; Riani Joyce Neves Nóbrega

Resumo: Este estudo objetivou analisar a vulnerabilidade de adolescentes à infecção pelo HIV/AIDS em escolares do município de Iguatu - CE. Para tanto, foi realizada uma pesquisa exploratória, descritiva com abordagem qualitativa com 12 adolescentes de uma Escola de Ensino Fundamental e Médio do município de Iguatu - CE. As informações foram obtidas no mês de junho de 2012, por meio de uma entrevista semiestruturada com grupo focal. Os resultados foram analisados através do Discurso do Sujeito Coletivo (DSC). A pesquisa respeitou a Resolução 196/96, do Conselho Nacional de Saúde. Na análise dos dados identificou-se que os sujeitos da pesquisa encontram-se na faixa etária de 17 a 19 anos de idade, sendo prioritariamente solteiros, cursando entre o $2^{\circ}$ e $3^{\circ}$ ano do ensino médio, alguns morando com familiares e apresentando renda familiar entre 1 e 5 salários mínimos. A prevenção contínua no discurso coletivo esteve diretamente ligada à duração $\mathrm{e}$ ao tipo de relacionamento, ou seja, ao passo que o relacionamento se torna mais duradouro, o uso do preservativo não se verifica mais nas relações sexuais. Ressaltam ainda que a principal forma de adquirir conhecimentos sobre a prevenção da AIDS são os meios de comunicação. É imperioso afirmar a necessidade de ações integradas e contínuas com os diversos segmentos sociais para que assim se possa, de maneira efetiva, criar condições e estratégias de enfrentamento para deter os avanços de contaminações pelo vírus HIV/AIDS cada vez mais frequente na população jovem do nosso país.

Palavras-Chaves: Adolescência; Vulnerabilidade; HIV/AIDS.

\section{Vulnerability Analysis of Teenagers to Infection Hiv / Aids In Iguatu - CE}

\begin{abstract}
This study aimed to analyze the vulnerability of adolescents to HIV / AIDS in school children of Iguatu - EC . EC - For this, an exploratory, descriptive qualitative research with 12 teenagers from a school of elementary and high school in the municipality of Iguatu was performed. The data were obtained in June 2012 by means of a semistructured interview with the focus group. The results were analyzed using the Collective Subject Discourse (CSD). The research complied with Resolution 196/ 96 of the National Health Council in the data analysis it was found that the subjects are in the age group $17-$ 19 years of age, being mainly singles, attending between $2^{\circ}$ and 3 rd year of high school, some living with family and having family income between 1 and 5 minimum wages. Continuous prevention in the collective discourse was directly linked to the length and type of relationship, ie, while the relationship becomes more lasting, condom use does not appear more in sexual intercourse . Also emphasize that the main way to acquire knowledge about AIDS prevention are the media . It is imperative to affirm the necessity of integrated and continuous with the various social segments so that you can, effectively, creating conditions and coping strategies to halt the advances of contamination by increasingly frequent virus HIV / AIDS in young people 's our country .
\end{abstract}

Key Words: Adolescence; Vulnerability, HIV / AIDS.

\footnotetext{
${ }^{1,3}$ Enfermeiro(a). Programa de Pós Graduação em Ciências da Saúde pela Faculdade de Medicina do ABC. Docente da Universidade Regional do Cariri (URCA) / Unidade Descentralizada de Iguatu-CE.

${ }^{2,4}$ Enfermeiro Assistencialista do Hospital Regional do Norte, Sobral-CE.

${ }^{5}$ Enfermeira docente da Universidade Regional do Cariri (URCA)/ Unidade Descentralizada de Iguatu
} 


\section{Introdução}

A adolescência é um período de transição entre a infância e a juventude, marcada por transformações biológicas e psíquicas, dentro de um contexto sociocultural. Deste modo, precisa ser levada a tal importância essa etapa como sendo indissociável para o processo de formação biopsicossocial, ou seja, fato que não pode ser separado de seus aspectos que são responsáveis para consolidação de sua personalidade (OSÓRIO, 1992). Diante dessas mudanças os adolescentes encontram-se marcados pelo quadro da vulnerabilidade frente aos inúmeros acontecimentos que acometem essa fase.

A vulnerabilidade, por sua vez, significa a capacidade do indivíduo ou do grupo social de decidir sobre sua situação de risco, estando diretamente associadas a fatores individuais, familiares, culturais, sociais, políticos, econômicos e biológicos (BRASIL, 2005a, p. 9).

Os adolescentes apresentam alta prevalência dos chamados comportamentos de risco para as Doenças Sexualmente Transmissíveis/Síndrome da Imunodeficiência Adquirida - DST’s/AIDS, como vida sexual precoce, múltiplos parceiros sexuais, relações sexuais desprotegidas, uso de álcool e drogas ilícitas. Alguns adolescentes ainda apresentam outras situações de risco relacionadas com a vulnerabilidade social, desemprego, baixa escolaridade, violência e falta de acesso amplo aos serviços de saúde. Esses e outros fatores como conhecimento deficiente sobre o uso do preservativo, gênero, falta de recursos para obtenção de preservativos, influência dos pares, uso de contraceptivo hormonal podem influenciar a uma maior vulnerabilidade (VIEIRA et al., 2004 apud MORAES, 2010).

Como a AIDS não apresenta manifestações imediatas após a relação sexual desprotegida, ou seja, os seus sintomas só aparecem tardiamente, pode passar a ser uma ameaça distante da realidade e isso acaba deixando a prevenção apenas para evitar a gravidez não planejada, assim apontada como um elemento que aumenta a vulnerabilidade dos adolescentes, principalmente no tocante a multiplicidade de parceiros, relações fixas com pessoas mais velhas e dentre outros fatores (TOLEDO; TAKAHASHI; GUANILO, 2011).

A AIDS é de caráter pandêmico, emergente e instável, aonde há mais de três décadas vem se mantendo e acometendo milhares de pessoas e desrespeitando fronteiras, economias e culturas, exigindo estudos no campo das ciências sociais e da saúde (OLIVEIRA; DIAS; SILVA, 2005). Tendo como agravante o indivíduo que permanecer infectado e sexualmente ativo transmitindo ocultamente durante vários anos, pelo fato da AIDS apresentar um período de incubação. Deste modo, supõe-se que parte significativa dos casos notificados na faixa etária entre 25 a 29 anos correspondem a indivíduos que se infectaram quando adolescentes, ou seja, existe um número bem maior de adolescentes infectados do que o percentual notificado (TOLEDO, 2008). 
O Ministério da Saúde identificou que jovens de 15 a 24 anos de idade notificados no Sistema de Informação de Agravos de Notificação (SINAN), declarados no Sistema de Informação sobre Mortalidade (SIM) e registrados no Sistema de Controle de Exames Laboratoriais (SISCEL) e Sistema de Controle Logístico de Medicamentos (SICLOM), de 1980 a junho de 2011, foram diagnosticados um total de 66.698 casos de AIDS no Brasil, estando 38.045 no sexo masculino (57,0\%) e 28.648 no sexo feminino $(43,0 \%)$ e tendo a região Nordeste 8.599 casos notificados (BRASIL, 2011a).

Uma estratégia para essa população refere-se ao Projeto Saúde e Prevenção nas Escolas (SPE) que tem como ação promover à integração dos sistemas de saúde e educação no ambiente escolar e também o propósito de promoção da saúde sexual e reprodutiva, o que inclui a distribuição de insumos nas escolas e materiais informativos seguidos de orientações, a formação continuada para os profissionais da saúde e educação em sexualidade, além de envolver a comunidade para atuar de forma unida para com seus filhos (BRASIL, 2011b).

Diante desse contexto questiona-se: quais os fatores que tornam os adolescentes vulneráveis ao HIV/AIDS? Quais as medidas de proteção usadas por esses adolescentes? Os adolescentes tem conhecimento suficiente para prevenção do HIV/AIDS e como foram adquiridas essas informações?

O tema do presente estudo foi escolhido após realização de um estágio no centro microrregional especializado de atenção a saúde reprodutiva e sexual (CEMEAR), local também especializado no atendimento a paciente com HIV/AIDS, onde surgiu a ideia de desenvolver uma pesquisa para avaliar a qualidade de vida, a partir das consequências biopsicossociais das pessoas portadoras do HIV. Sendo que, isso não foi possível, pelo fato da resistência e medo da repreensão caso a sociedade saiba da sua soropositividade e o risco que é para com os demais. Por conta de tal fato, foi que se decidiu trabalhar com a vulnerabilidade dos adolescentes para o HIV/AIDS, em virtude dos problemas que acometem essa etapa da vida, assim como a necessidade de trabalhos científicos voltados para essa área em questão.

A busca de diversos conteúdos para produção dessa pesquisa permitiu constatar que além da adolescência ser uma fase da vida marcada pelas mudanças biopsicossociais é também uma batalha de desafios com a sociedade que repreende, descrimina, desacredita e exige de sua sexualidade sem perceber do déficit cognitivo e dos riscos que provocam no desenvolvimento dos adolescentes. Por isso, apesar da grande variedade de instituições governamentais e não governamentais trabalharem a conscientização das medidas de promoção e prevenção para assuntos que dão ênfase às DST's, gravidez não planejada, drogas e sexualidade com os adolescentes e jovens, isso não tem sido suficiente, pois para que isso aconteça faltam trabalhos voltados com os pais e comunidades que veem o assunto com resistência e como desnecessário, podendo essa ausência influenciar numa decisão precoce para iniciar sua vida sexual ou na tomada de decisão frente a uma situação de risco, 
lembrando que a mídia e a sociedade passam essa informação de forma distorcida, obscura e deficiente em sua completa realidade.

Vista a importância do assunto, é que se justifica a razão da escolha dessa pesquisa, porque não só de fato servirá para levantar dados que fazem referência a problemas decorrentes da diferença socioeconômica, cultural, saúde e educação, mas principalmente para os profissionais da atenção básica em saúde e educadores escolares que vivenciam as realidades e reconhecem as necessidades das comunidades, assim sendo capazes de atuarem no processo de transformação frente à proteção, prevenção e promoção da saúde, ou seja, reduzindo a vulnerabilidade desses adolescentes e jovens que estão expostos a riscos que a sociedade construiu no decorrer dos anos.

Mediante o pressuposto, este estudo teve como objetivo analisar a vulnerabilidade de adolescentes à infecção pelo HIV/AIDS em escolares do município de Iguatu - CE.

\section{Método}

Trata-se de uma pesquisa do tipo exploratória, de caráter descritivo com abordagem qualitativa.

O presente estudo foi realizado na Escola de Ensino Fundamental e Médio Antônio Albuquerque de Souza Filho, situada na Vila Centenário da cidade de Iguatu - CE.

A população foi constituída de 12 adolescentes da presente escola. A amostra ficou formada pelos adolescentes que se dispuserem a participar da pesquisa, tendo como critérios de inclusão: adolescentes de ambos os sexos com idade de 14 a 19 anos; adolescentes que estejam cursando o ensino médio; e que participem do SPE.

Os dados foram coletados no mês de junho desse mesmo ano, através de uma entrevista semiestruturada com grupo focal. Sendo que para sua análise foi utilizado à proposta de técnica do Discurso do Sujeito Coletivo (DSC), em que obtemos as expressões - chaves (ECH), a ideia central (IC) e o DSC.

Os aspectos éticos da pesquisa foram conduzidos de acordo com as normas do conselho nacional de saúde, que cumpre os requisitos da resolução $\mathrm{N}^{\circ}$ 196/96, que cuidam das pesquisas envolvendo seres humanos (BRASIL, 1996). 


\section{Análise e Discussão dos Dados}

\section{Caracterização da amostra}

A formação do grupo teve um total de doze estudantes, com idades que variavam de dezessete a dezenove anos, onde cinco desses tinham dezessete anos, outros cinco com idade de dezoito anos e o restante com dezenove anos, caracterizando uma amostra puramente adolescente.

No que se reporta à situação conjugal, oito desses participantes se julgaram solteiros, entretanto, é pertinente destacar que os mesmos mantinham encontros amorosos casuais sem compromisso com a parte envolvida. Nesses termos, o individuo encontra-se vulnerável, pois não é o seu estado civil que vai determinar o grau de vulnerabilidade e sim o comportamento adotado frente ao relacionamento conjugal descompromissado.

O contexto do relacionamento é um elemento determinante no uso ou não de preservativo pelos adolescentes, pois o uso da camisinha, método preferido, está associado às relações sexuais esporádicas, sem parceiro (a) fixo. Já quando se trata da namorada ou esposa, a camisinha é substituída pela confiança, recorrendo-se à pílula para se evitar a gravidez indesejada, entretanto adquirir alguma doença não está em pauta nessa situação, tornando-os, portanto, vulneráveis as Doenças Sexualmente Transmissíveis e ao HIV/AIDS (ALVES e BRANDÃO, 2009).

Quanto à escolaridade evidenciou-se que todos os participantes do grupo cursavam o ensino médio, sendo essa a categoria de ensino esperada para a população adolescente.

Camargo e Ferrari (2009) veem a escola como um lugar importante e formidável para se trabalhar conhecimentos, habilidades e mudanças de comportamento, pois é o local onde os adolescentes permanecem o maior tempo do seu dia

A escolaridade é importante fator para evitar disseminação das DST's/AIDS, visto que os adolescentes que não estão inseridos nas escolas são mais suscetíveis de adotar comportamento de risco, uma vez que detêm menos informação e, por conseguinte, mais mitos em relação à infecção pelo HIV/AIDS, além de terem dificuldade de mudar suas crenças devido a informações reduzidas (NUNES e ANDRADE, 2009).

De todos que fizeram parte do estudo, observou-se que a maioria morava com os pais, cinco (05), inclusive a única pessoa casada do grupo; três (03) moravam apenas com a mãe; dois (02) residiam com a avó; um (01) sujeito morava com amiga e um (01) coabitava com o patrão.

A família é a base para a formação pessoal e cultural do ser humano; em sua ausência o mesmo ficará aos cuidados e educação da sociedade, assim tornando-os mais vulneráveis para o HIV/AIDS, pois as características dessa fase da vida associado à falta de repreensões e disciplina, os 
torna possíveis vítimas de agravos e riscos que podem ser evitados (BESERRA; PINHEIRO; ALVES, 2008).

Heilborn e colaboradores (2006) destacam que, quando as mulheres trocam informações com suas mães durante a fase de socialização da sexualidade, o nível de comunicação como parceiro tende a ser mais elevado, contribuindo para um exercício de sexualidade mais responsável e seguro .

A maioria dos pais não consegue conversar sobre sexualidade nem acerca da prática sexual segura com os adolescentes em razão de vários fatores, entre eles: falta de informações sobre DST's, timidez, ausência de diálogo entre pais e filhos, falta de liberdade com os filhos em virtude da cultura na qual eles vivem, pois veem o sexo como tabu. Por conta disso, a escola tende a apresentar um papel que oriente os adolescentes a ter uma vida saudável, uma vez que é um importante local para a discussão e debate dos temas em questão.

Quanto à renda familiar, evidenciou-se que a maioria possui entre 1 e 2 salários mínimos. A situação socioeconômica associada à desestruturação familiar põe em risco a formação dos adolescentes, pois a deficiência de conhecimento, a promiscuidade e a falta de expectativas para o futuro dentre outros fatores está ligado diretamente à vulnerabilidade para o HIV/AIDS.

Os adolescentes e jovens de baixo nível de instrução e baixo nível socioeconômico são mais susceptíveis às infecções sexualmente transmissíveis, visto que a grande maioria não tem perspectivas de vida, de tal modo que não apresentam preocupações e precauções para fatores de risco da AIDS GRIEP; ARAÚJO; BATISTA, (2005).

\section{Discurso do sujeito coletivo em resposta a seguinte pergunta: $O$ que vocês entendem sobre} AIDS?

\begin{tabular}{l|l}
\hline \multicolumn{1}{c|}{ Ideia Central } & \multicolumn{1}{c}{ DSC } \\
\hline - Doença sexualmente transmissível, & $\begin{array}{l}\text { [...] A AIDS é uma doença transmitida através da } \\
\text { relação sexual desprotegida e utensílios } \\
\text { injetáveis, marcada pelo seu poder de revolta } \\
\text { messoal, pelo preconceito que é decorrente da } \\
\text { falta de conhecimento da população e por ser } \\
\text { uma doença silenciosa, porém com grande } \\
\text { capacidade de transmissão mesmo não tendo } \\
\text { apresentado nenhuma sintomatologia [...]. }\end{array}$ \\
\hline
\end{tabular}

A ideia central do quadro 03 mostra por meio do DSC que os adolescentes conhecem a AIDS, pois afirma ser uma doença transmitida por contato sexual, principalmente e, que o surgimento das manifestações clínicas leva tempo, fato este que expõe o jovem a uma vulnerabilidade maior.

Embora os adolescentes tivessem conhecimento acerca da transmissão e das formas de prevenção à infecção, notou-se um desacerto entre suas informações a respeito da AIDS e a prática de 
medidas de prevenção. Outro elemento da vulnerabilidade dos adolescentes ao HIV que pode ser apontado é o aparecimento dos sintomas tardiamente, uma vez que a AIDS não é percebida como uma consequência imediata da relação sexual desprotegida. Os adolescentes passam a considerá-la uma ameaça distante de sua realidade deixando a prevenção em segundo plano.

A AIDS, além de ter como grave problema as consequências físicas e psicológicas, é também um fenômeno de natureza social que vai desde o isolamento, o abandono, a rejeição social até a morte, onde isso tem seus efeitos fundamentados nos estigmas socialmente construídos e intimamente ligados as representações sociais da doença (CASTANHA et al., 2006).

\section{Discurso do sujeito coletivo em resposta a seguinte pergunta: Como a AIDS é transmitida?}

\begin{tabular}{c|l}
\hline \multicolumn{1}{c|}{ Ideia Central } & \multicolumn{1}{c}{ DSC } \\
\hline de sangue e utensílios contaminados. & $\begin{array}{l}\text { [...] A transmissão muitas vezes ocorre por meio } \\
\text { da relação sexual sem uso do preservativo, } \\
\text { podendo ser essa relação de heterossexuais ou } \\
\text { homossexuais, fluidos sanguíneos, beijo na boca } \\
\text { no caso quando possui uma porta de entrada, a } \\
\text { exemplo disso um corte ou dente quebrado, } \\
\text { também através de utensílios perfuro cortantes } \\
\text { que são reutilizados em hospitais, clínicas } \\
\text { dentárias, tatuadores, manicures e em } \\
\text { transfusóes sanguíneas [...]. }\end{array}$ \\
\hline
\end{tabular}

A ideia central do quadro 04 revela por meio do DSC que os adolescentes têm domínio das principais formas de transmissão, sendo que novamente algumas informações apresentam-se errôneas.

Em um estudo com 826 adolescentes para avaliação dos conhecimentos, atitudes e comportamentos de risco a respeito da AIDS, identificou-se que a principal forma de transmissão é a via sexual, $81 \%$ com pessoa infectada, $73 \%$ através das relações sexuais e com valor próximo situamse aqueles que mencionaram através de seringas usadas por outros, e nos hospitais $66 \%$, através de transfusão de sangue 64\%, e ainda através de lâminas e elementos perfuro cortantes 62\% (ALMEIDA; SILVA; CUNHA, 2005).

Uma vez que o indivíduo está apto para doação, ele é encaminhado para coleta, e em seguida, a bolsa de sangue será enviada para o setor de processamento, onde ocorrerá a separação do sangue total em componentes sanguíneos. Com os tubos de amostras coletados, seu sangue é classificado por tipo $\mathrm{ABO}$ e fator $\mathrm{Rh}$, e estará submetido a exames exigidos por lei, a fim de evitar a transmissão de doenças através do sangue. Os exames realizados são para AIDS, hepatites B e C, chagas, sífilis, mielopatia espática tropical ( $\underline{\text { HTLV }) ~ e n t r e ~ o u t r o s . ~ T a m b e ́ m ~ s e r a ́ ~ f e i t a ~ u m a ~ p e s q u i s a ~ d e ~ h e m o g l o b i n a s ~}$ anômalas. Após a realização dos testes e, sendo todos eles negativos, o sangue segue para o setor de liberação, e ficará aguardando para transfusão (BARBOSA et al., 2009). 
Discurso do sujeito coletivo em resposta a seguinte pergunta: Quais as medidas de proteção contra a AIDS?

\begin{tabular}{l|l}
\hline \multicolumn{1}{c|}{ Ideia Central } & \multicolumn{1}{c}{ DSC } \\
\hline $\begin{array}{l}\text { F Fazer uso do preservativo e não ter } \\
\text { relação com qualquer pessoa. }\end{array}$ & $\begin{array}{l}\text { [...] Ter relação sexual sempre com camisinha, } \\
\text { conhecer histórico de vida, abstinência sexual, } \\
\text { não ter relação ou beijar pessoas desconhecidas } \\
\text { e o diálogo [...]. }\end{array}$ \\
\hline
\end{tabular}

A ideia central do quadro 05 relata por meio do DSC que os adolescentes conhecem o preservativo como primeira opção para prevenção, sendo o comportamento social e sexual do parceiro a outra opção mais verbalizada.

A promiscuidade, portanto é vista como forma de vulnerabilidade a AIDS e está associada a pessoas que tem um comportamento irresponsável, ou seja, o fato de se manter relações sexuais com grande quantidade de parceiros aumenta a probabilidade de um contato com o HIV (BARRETO; SANTOS, 2009).

Embora os adolescentes conheçam as medidas de proteção contra o HIV/AIDS e possua o preservativo no ato sexual, isso não significa que as medidas corretas sejam tomadas ou incorporadas no cotidiano de sua vida sexual (MORAES, 2010). Até porque na maioria das vezes não se usa o preservativo de forma contínua em todo ato sexual e em todas as relações. É necessário que as atividades educativas propostas pelos Ministérios da Saúde e Educação sejam de fato implementadas no cotidiano desses profissionais e adolescentes visando um melhor diálogo e prevenção de agravos sexuais.

Discurso do sujeito coletivo em resposta a seguinte pergunta: A prevenção é contínua em todas as relações sexuais?

\begin{tabular}{c|l}
\hline \multicolumn{1}{c|}{ Ideia Central } & \multicolumn{1}{c}{ DSC } \\
\hline \multirow{2}{*}{ Não, depende do tipo de relacionamento. } & $\begin{array}{l}\text { [...] A prevenção só é contínua quando ambos } \\
\text { não têm nenhum vínculo afetivo ou não se } \\
\text { conhecem, pois quando passam a ficar com mais } \\
\text { frequência ou desenvolvem algum sentimento, } \\
\text { isso gera um motivo para a relação náo ter mais } \\
\text { o uso do preservativo e sim algum método } \\
\text { contraceptivo hormonal, já que a maioria dos } \\
\text { homens se queixa do desconforme que a } \\
\text { camisinha traz }[. . .] .\end{array}$ \\
\hline
\end{tabular}

A ideia central do quadro 06 descreve por meio do DSC que a prevenção contínua está diretamente ligada ao tipo de relacionamento, ou seja, passou a ter um compromisso mais longo e 
duradouro, consequentemente passa a não mais usar o preservativo. Portanto, o preservativo no início é a primeira opção de escolha para todos os casais, porém depois de certo tempo não é mais visto como bem vindo à relação, colocando assim em risco a sua vida e a vida do seu parceiro.

Os adolescentes, principalmente do sexo masculino demonstraram ter maior intimidade com o preservativo, inclusive os cuidados antes e após o seu uso. E enfatizam que apenas o uso da camisinha é feito quando a parceira ou parceiro tem um comportamento sexual promíscuo ou quando ocorre relação sexual esporádica por motivo banal. Porém, quando tornam a relação estável ocorre o desuso do preservativo apenas confiando na fidelidade do parceiro.

O fato de assumir o compromisso do namoro parece funcionar como atestado de segurança, passando a ter cuidado apenas para não ocorrer uma gravidez, de tal modo dispensando a prevenção e desconsiderando outros relacionamentos anteriores, o que não confere imunidade a nenhuma das partes (KOERICH et al., 2010).

Discurso do sujeito coletivo em resposta a seguinte pergunta: Quais os fatores que vocês consideram de risco para AIDS?

\begin{tabular}{|c|c|}
\hline Ideia Central & DSC \\
\hline - $\quad$ Relação sexual desprotegida; & $\begin{array}{l}\text { [...] É "transar" sem o uso de preservativo em } \\
\text { todas as relações, principalmente com pessoas } \\
\text { desconhecidas ou que tenham uma vida } \\
\text { promíscua [...]. }\end{array}$ \\
\hline Vida sexual precoce; & $\begin{array}{l}\text { [...] Isso está relacionado à influência de } \\
\text { amigos, desestruturação familiar ou ausência da } \\
\text { família na construção do adolescente e por fim a } \\
\text { falta de maturidade para usar o preservativo } \\
\text { [...]. }\end{array}$ \\
\hline Namorar pessoas mais velhas; & $\begin{array}{l}\text { [...] Muitos adolescentes, principalmente do sexo } \\
\text { feminino acabam namorando pessoas mais } \\
\text { velhas, e por influência dos mesmos e diferença } \\
\text { de gênero a mulher acaba perdendo o poder de } \\
\text { decisão de quando iniciar a sua vida sexual e } \\
\text { isso associado ao medo de perder o namorado } \\
\text { acaba se rendendo ao convencimento dos } \\
\text { homens [...]. }\end{array}$ \\
\hline O uso de bebidas alcoólicas; & $\begin{array}{l}\text { [...] O uso de bebidas alcoólicas ou qualquer } \\
\text { outra droga faz com que o indivíduo perca sua } \\
\text { capacidade de discernir o que é certo ou errado } \\
\text { e acabam que não "ligam" para possiveis riscos } \\
\text { oriundos de uma relação desprotegida [...]. }\end{array}$ \\
\hline Falta de informações; & $\begin{array}{l}\text { [...] A falta de conhecimento, ausências dos pais } \\
\text { no tocante a suprir essa carência e a deficiência } \\
\text { de educação em saúde geram um grande fator de } \\
\text { risco para AIDS [...]. }\end{array}$ \\
\hline
\end{tabular}


[...] A multiplicidade de parceiros é um dos principais fatores de risco, pois o que se observa é que quanto maior o numero de parceiros sexuais maiores são os riscos de adquirir a AIDS. Onde atualmente a AIDS vem se feminizando por consequência da quantidade de parceiras que os homens têm [...].

A ideia central 01 vem afirmar através do discurso que ter relação sem o uso do preservativo é o principal fator e meio de risco de se contrair a AIDS.

A noção dos riscos advindos de relações sexuais desprotegidas é fundamental para que os adolescentes possam vivenciar o sexo de maneira segura e saudável, garantindo a prevenção da gravidez indesejada e das DST's/AIDS, além de ser um direito que possibilita cada vez mais, ao ser humano, o exercício da sexualidade desvinculado da procriação (SALDANHA et al., 2008).

A ideia central 02 discursa que os adolescentes não estão preparados psicologicamente para assumir responsabilidades de ter vida sexualmente ativa. Daí a importância da educação em saúde com os pais e seus filhos sobre sexualidade na adolescência.

A antecipação da idade para iniciar a vida sexual tem sido um fator de risco, pois tem se observado uma maturação biológica mais rápida que o cognitivo e emocional, e isso vem acarretar consequências que podem levar a uma gravidez não planejada e riscos de contaminação por doenças sexualmente transmissíveis, pois se soma ao fato de não haver um uso consistente de métodos contraceptivos e protetores para as doenças (CAMARGO; FERRARI, 2009).

A ideia central 03 relata que principalmente as meninas namoram com homens mais velhos e por isso tem relação mais cedo por conta da exigência sexual no namoro.

Borges e Schor (2005), em seu estudo com 406 jovens entre 15 e 19 anos, observaram que adolescentes de ambos os sexos iniciaram sua vida sexual com parceiros (as) mais velhos (as), porém cabe ressaltar que a diferença de idade entre os adolescentes e seu primeiro parceiro foi bem maior entre as mulheres do que entre os homens. Essa diferença de idade, principalmente para as mulheres acarreta perdas no poder de negociação de quando iniciar sua sexualidade, assim como de decidir a necessidade ou não de proteção na relação sexual.

A ideia central 04 mostra o álcool como um forte promotor da vulnerabilidade para contrair a AIDS, pois acarreta perdas na sua decisão frente aos riscos e, por conseguinte levando os mesmos a não fazerem uso do preservativo na maioria das vezes, até porque os efeitos da bebida interferem diretamente na forma correta e contínua de seu uso.

Um estudo realizado no Estado de Pernambuco identificou que as pessoas que bebem frequentemente contraem mais o vírus do HIV do que pessoas que não fazem o uso do álcool, apesar de conhecerem as formas de transmissão e prevenção da doença (BRASIL, 1999). 
A ideia central 05 ressalta que a falta de informação, seja por educação escolar, familiar, em saúde e ambiente social, influencia diretamente como fator de risco.

As mudanças dessa fase da vida fazem com que os adolescentes vivam fortemente sua sexualidade, tornando-se evidente muitas vezes através de práticas sexuais desprotegidas, podendo provocar inúmeros problemas devido à falta de educação nas principais instituições de ensino que são a família e a escola (CAMARGO; FERRARI, 2009).

A ideia central 06 discursa que a diversidade de parceiros sexuais constitui também um risco e que na sociedade o homem se destaca nesse aspecto por ser mais infiel.

A multiplicidade de parceiros, principalmente os homens e a pouca utilização de preservativos, associada a uma maior liberdade sexual, são alguns dos fatores conhecidos que podem contribuir para aumentar a vulnerabilidade das adolescentes as DST/AIDS (BARRETO; SANTOS, 2009).

Discurso do sujeito coletivo em resposta a seguinte pergunta: De onde vocês adquiriram esses conhecimentos?

\begin{tabular}{c|l}
\hline \multicolumn{1}{c|}{ Ideia Central } & \multicolumn{1}{c}{ DSC } \\
\hline \multirow{2}{*}{$\begin{array}{l}\text { Meios de comunicação e pessoas } \\
\text { diversas. }\end{array}$} & {$[\ldots]$ Através da mídia, palestras nas escolas, } \\
mães, amigos, filmes e por meio da sociedade \\
{$[\ldots]$.}
\end{tabular}

Na ideia central do Quadro 08 os adolescentes obtêm seus conhecimentos de várias formas e de acordo com suas necessidades adquirem informações incompletas e desestruturadas.

Com os tempos modernos, a liberação dos costumes, a influência de amigos, associada à erotização da mídia e exigências da sociedade incentivam a iniciação sexual cada vez mais precoce, o que também contribui para o aumento das chances de adolescentes e jovens adquirirem DST's/AIDS, uma vez que, quanto menor a idade tende a possuir menor informação e a apresentar um preparo psicológico mais frágil (OLIVEIRA et al., 2009).

\section{Considerações Finais}

A Síndrome da Imunodeficiência Adquirida (AIDS) é uma doença causada por um vírus, o Vírus da Imunodeficiência Humana (HIV), que leva a comprometer o funcionamento do sistema imunológico humano, impedindo-o de executar seu trabalho adequadamente, que é de protegê-lo contra agentes causadores de doenças sejam: bactérias, vírus, parasitas e até mesmo as células 
cancerígenas. Com o progressivo prejuízo do sistema imunológico o organismo humano se torna cada vez mais debilitado e susceptível as doenças oportunistas, que acabam por levar o indivíduo à morte.

O que caracteriza um grande problema da AIDS relacionada aos adolescentes é o seu período de latência longo e variável desde a infecção pelo HIV até o aparecimento de infecções relacionadas com o HIV/AIDS. Por conseguinte, pessoas portadoras do HIV podem permanecer meses ou anos sem apresentar quaisquer sinais da doença e, no entanto, serem transmissores do vírus.

O conhecimento a respeito da AIDS de forma ampla e correta é um fator primordial para prevenção de riscos e agravos decorrentes da promiscuidade e desconhecimento das pessoas das inúmeras formas de transmissão. Os resultados obtidos da pesquisa mostram que a população de 14 a 19 anos é bastante propícia de serem acometidos pelo HIV/AIDS, pois essa é uma fase de descobertas e curiosidades, em que o desejo de vivenciar situações sexuais é marcante nesse período etário.

A transmissão da AIDS ocorre por meio de relações sexuais desprotegidas (vaginal, oral ou anal), com pessoas infectadas, apresentando sintomas ou não, compartilhando seringas e agulhas com alguém contaminado, de mãe portadora do HIV para seu filho durante a gravidez, parto e/ou amamentação e através de perfuro cortantes não esterilizados ou infectados pelo vírus. Para essas formas de transmissão destaca-se que os adolescentes sabem identificar a maioria, mas nem todas, o que outra vez os colocam em riscos por apenas apresentar subsídios superficiais a respeito do tema.

A principal fonte de transmissão tem sido as relações sexuais e o método mais eficiente para prevenção é o preservativo, onde se observa uma larga divulgação e distribuição gratuita pelo Ministério da Saúde.

Em relação às medidas de proteção contra a AIDS os adolescentes demostram e conhecem que o uso da camisinha em todos os tipos de relação sexual, seja vaginal, anal ou oral associado à pessoa certa, contribuirá em muito para sua proteção individual e de seu parceiro.

Porém, a prevenção contínua em todas as relações não é possível, até porque quando se passa a ter uma relação mais séria, esse preservativo é desvinculado do ato sexual e consequentemente sobrevindo o uso de qualquer outro método contraceptivo hormonal, pois com o tempo se desenvolve a confiança e o amor ao parceiro, esquecendo-se do seu passado sexual e atentando-se apenas para uma gravidez não planejada.

Os adolescentes consideram alguns fatores como sendo de risco para AIDS dentre eles destaca-se: relação sexual desprotegida, vida sexual precoce, envolvimento com pessoas mais velhas, uso de bebidas alcoólicas, falta de informações e multiplicidade de parceiros. Esses jovens conhecem e têm opinião a respeito dos temas em questão, porém não vinculam todos esses fatores como riscos para uma possível exposição ao HIV. Na realidade o que se observa é que na prática todos os conceitos são esquecidos e deixados para trás quando se vivencia alguma situação que envolva comportamento sexual. 


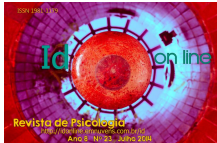

Este estudo possibilitou conhecer a realidade dos adolescentes frente aos aspectos da AIDS, onde a influência dos meios de comunicação, amigos, ausência dos pais quanto à orientação sobre sexualidade com os filhos, os expõem a riscos de contrair o HIV/AIDS. Portanto, considera-se que, embora se tenham vários programas públicos objetivando o trabalho da saúde em conjunto com a educação escolar, ainda se verifica a deficiência de conhecimentos dos adolescentes em relação à sexualidade no geral, o que nos faz buscar e implementar cada vez mais estratégias de educação visando a prevenção e promoção da saúde, para que esses adolescentes construam e vivenciem sua cidadania de maneira equilibrada e salutar.

\section{Referências}

ALVES CA, BRANDÃO ER. Vulnerabilidades no uso de métodos contraceptivos entre adolescentes e jovens: interseções entre políticas públicas e atenção à saúde. Cien Saude Colet 2009; 14 (2): 661670.

ALMEIDA ADL, SILVA CF, CUNHA GF. Os adolescentes e o VIH/SIDA: estudo sobre os conhecimentos, atitudes e comportamentos de saúde relativos ao VIH/SIDA. Rev Port Saude Pub 2005; 23( 2): 105-112.

BARBOSA SOB, BALMANT MF, NARDIN JÁ, LINDANI KCF. Do doador ao receptor: o ciclo do sangue. Cadernos da Escola de saúde, Curitiba, 2: 1-10, 2009.

BARRETO ACM, SANTOS RS. A vulnerabilidade da adolescente às doenças sexualmente transmissíveis: contribuições para a prática da enfermagem. Esc Anna Nery Rev Enferm 2009; 13 (4): 809-16.

BESERRA EP, PINHEIRO PNC, ALVES MDS. Adolescência e vulnerabilidade às doenças sexualmente transmissíveis: uma pesquisa documental. DST - J bras Doenças Sex Transm 2008; 20(1): 32-35.

BORGES ALV, SCHOR N. Início da vida sexual na adolescência e relações de gênero: um estudo transversal em São Paulo, Brasil, 2002. Cad Saude Pub 2005; 21(2): 499-507.

BRASIL. Conselho Nacional da saúde, Resolução $\mathbf{N}^{\circ}$ 196, de 10 de outubro de 1996: Diretrizes e Normas regulamentadoras de pesquisas em seres humanos. Bioética. Brasília: MS; 4(2): 1996.

BRASIL. Ministério da Saúde - Secretária de Políticas de Saúde - Área de Saúde do Adolescente e do Jovem. Cadernos juventude, saúde e adolescência. Brasília: MS; 1999.

BRASIL. Ministério da Saúde, Secretaria de Atenção á Saúde, Área de Saúde do Adolescente e do Jovem. Marco legal: saúde um direito de adolescentes. Série A. Normas e Manuais Técnicos. Brasília:MS; 2005.

BRASIL. Ministério da Saúde. Boletim Epidemiológico AIDS e DST 2011 a. [internet]. Disponível em: http://www.aids.gov.br/index.html. Acesso em: 29 de dez. de 2011a. 


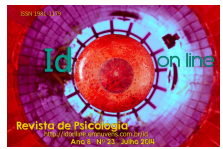

http://idonline.emnuvens.com.br/id

ISSN on-line: 1981-1179

BRASIL. Ministério de Saúde. Boletim Epidemiológico AIDS e DST 2011 b. Disponível em: http://www.aids.gov.br/index.html. Acesso em: 29 de dez. 2011 b.

CAMARGO EAI, FERRARI RAP. Adolescentes: conhecimentos sobre sexualidade antes e após a participação em oficinas de prevenção. Cien Saude Colet 2009; 14 (3): 937 - 946.

CASTANHA AR, COUTINHO MPL, SALDANHA AAW, RIBEIRO CG. Aspectos psicossociais da vivência da soropositividade ao HIV nos dias atuais. Psico 2006; 37(1): 47-56.

GRIEP RH, ARAÚJO CLF, BATISTA SM. Comportamento de risco para a infecção pelo HIV entre adolescentes atendidos em um centro de testagem e aconselhamento em DST/AIDS no Município do Rio de Janeiro, Brasil. Epidemiol. Serv. Saúde 2005; 14(2): 119 - 126.

HEILBORN ML, AQUINO EML, BOZON M, KNAUTH DR. O aprendizado da sexualidade. Reprodução e trajetórias sociais de jovens Brasileiros. Rio de Janeiro: Fiocruz/Garamond, 2006.

KOERICH MS, BAGGIO MA, BACKES MTS, BACKES DS, CARVALHO JN, MEIRELLES BHS, ERDMANN AL. Sexualidade, doenças sexualmente transmissíveis e contracepção: atuação da enfermagem com jovens de Periferia. Rev Enferm UERJ,2010; 18(2): 265-71.

NUNES ELG, ANDRADE AG. Adolescentes em situação de Rua: prostituição, drogas e HIV/AIDS em Santo André, Brasil. Psicol Socied 2009; 21 (1): 45-54.

OSÓRIO LC. ADOLESCENTES hoje. 2 ed. Porto Alegre (RS): Artes Médicas; 1992.

OLIVEIRA SHS, DIAS MR, SILVA MIT. Adolescentes e AIDS: fatores que influenciam a intenção de uso do preservativo. DST- J bras Doença Sex transm. 2005; 17(1): 32-38.

OLIVEIRA DC, PONTES APM, GOMES AMT, RIBEIRO MCM. Conhecimentos e Práticas de adolescentes acerca da DST/HIV/AIDS em duas escolas públicas municipais do Rio de Janeiro. Esc Anna Nery RevEnferm, 2009; 13(4):833-41.

SALDANHA AAW, CARVALHO EAB, DINIZ RF, FREITAS ES, FÉLIX SMF, SILVA EAA. Comportamento sexual e vulnerabilidade à AIDS: um estudo descritivo com perspectiva de práticas de prevenção. DST - J bras Doenças Sex Transm; 2008; 20(1): 36-44.

TOLEDO MM. Vulnerabilidade de adolescentes ao HIV/ AIDS: revisão integrativa. [dissertação] São Paulo: Universidade de São Paulo; 2008.

TOLEDO MM, TAKAHASHI RF, GUANILO MC. Elementos de vulnerabilidade individual de adolescentes ao HIV/AIDS. Rev Bras Enferm, 2011; 64(2): 370-5.

\section{Como citar esse artigo (ABNT):}

FERREIRA, Natália B.; COSTA, Israel F.; LUNA NETO, Raimundo T.; FREITAS, Leonardo F.; NÓBREGA, Riani J.N. Análise da Vulnerabilidade de Adolescentes à Infecção pelo HIV/AIDS em Iguatu - CE. Id on Line Revista de Psicologia, Julho de 2014, vol.8, n.23, p. 195-208- ISSN 1981-1179. 